\title{
An empirical formula for predicting the collapse strength of composite cylindrical-shell structures under external pressure loads
}

\author{
Yoon Sik Cho ${ }^{1,2}$, Do Han $\mathrm{Oh}^{3}$ and Jeom Kee Paik ${ }^{2,4,5^{*}}$ \\ ${ }^{1}$ Agency for Defense Development, Daejeon 34186, Republic of Korea \\ ${ }^{2}$ Department of Naval Architecture and Ocean Engineering, Pusan National University, \\ Busan 46241, Republic of Korea \\ ${ }^{3}$ Department of Naval Architecture, Ocean \& Marine Engineering, University of Strathclyde, \\ Glasgow G11 XQ, UK \\ ${ }^{4}$ The International Centre for Advanced Safety Studies (The Lloyd's Register Foundation \\ Research Centre of Excellence), Busan 46241, Republic of Korea \\ ${ }^{5}$ Department of Mechanical Engineering, University College London, London WC1E 7JE, \\ UK \\ * Corresponding author. J.K. Paik. (Email) jeompaik@gmail.com
}

\begin{abstract}
This paper derives an empirical formula for predicting the collapse strength of composite cylindrical-shell structures under external hydrostatic pressure loads as a function of geometric dimensions and layered angles, where the effects of initial manufacturing imperfections are implicitly taken into account. A series of experiments are undertaken on $[ \pm \theta / 90] \mathrm{Fw}$ filament-wound-type composite cylindrical-shell models subjected to collapse pressure loads. A total of 20 composite cylindrical-shell models are tested to derive the empirical formula, which is validated by comparison with experimental data, existing design formulas of ASME 2007 and NASA SP-8700, and solutions of the nonlinear finite element method. It is concluded that the proposed formula accurately predicts the collapse pressure loads of filament-wound composite cylinders and will thus aid the safety design of composite cylindrical shell-structures under external pressure loads.
\end{abstract}

Keywords: Composites, cylindrical-shell structure, collapse strength, filament-wound cylinder, external hydrostatic pressure load

\section{Introduction}

Underwater vehicles are increasingly needed for ocean exploration and subsea operations, and at ever greater depths. Resistance to the high hydrostatic pressures around underwater vehicles is mainly provided by the pressure hull structure (Aguirre et al. 2017). The deeper the vehicles descend into the water, the greater the necessary structural weight and, therefore, the lesser the payloads that can be carried. To enable effective pressure endurance while carrying heavier loads, composite materials are often used to construct the pressure hulls of underwater vehicles. Composite design technologies have long been applied to build surface combat ships and submarines, taking advantage of the high specific strength, corrosion resistance, structural design availability, and light weight of composite materials (Mouritz et al. 2001, Rais-Rohani and Lokits 2007). 
Deep submersible vehicles have a composite cylindrical-pressurehull, which can effectively resist high external hydrostatic pressure. Previous studies have shown that structural buckling induced by high hydrostatic pressure is the major risk factor in underwater sea environments for deep submersibles with long pressure hulls (Perry et al. 1992, Graham 1996, Liang et al. 2003)

In composite cylindrical-shell structures, the composition of the plies plays an important role in the bearing capacity of the laminates. Many studies have focused on the development of analytical plate and shell theories, e.g., classical lamination theory (CLT) (Jones 1999), thick/thin shell theories(reviewed in Qatu et al. 2012), and layerwise shell theory(Reddy 1984). Barbero and Reddy (1990) presented a generalized 2-dimensional theory of laminated cylindrical shells accounting for discontinuities at the interfaces of laminates. Soldatos (1992) derived the governing equations for the nonlinear analysis of laminated composite cylindrical shells regarding the transverse shear deformation.

The limit of stability is the major design criterion of submersible cylindrical hulls. Therefore, the numerical and experimental research into the buckling phenomenon has focused on estimating the buckling pressure of composite cylinders. Papadakis (2008) presented an analytical stability equation based on higher-order shell theory for thick cylindrical shells, considering the effects of transverse shear and nonlinear variation of the stresses and displacements. Nguyen et al. (2009) derived an asymptotic formula as a function of the thickness non-uniformity parameter for cylindrical-shell buckling. Li and Lin (2010) calculated the nonlinear buckling and post-buckling of a moderately thick anisotropic laminated cylindrical shell based on a higher-order shear deformation shell theory. Hur et al. (2008), Moon et al. (2010), and Kim et al. (2010) investigated the post-buckling behavior and failure of filament-wound composite cylinders using the nonlinear finite element method (NLFEM) and experiments. Deyet al. (2014) numerically analyzed the post-buckling characteristics of moderately thick-walled composite cylinders using NLFEM. Several researchers (Schilloet al. 2015, Castro et al. 2015, Blachut 2016) have shown experimentally and numerically that manufacturing imperfections influence the buckling loads of composite cylinders. The buckling strength of composite cones and domes, which are important structural components of the pressure hull, has been investigated in association with initial geometric imperfections by Castro et al. (2015) and Blachut (2016).

Furthermore, several studies have developed approaches based on analytical formulations that allow designers to quickly and reliably predict buckling loads (Perry et al. 1992, ASME 2007, NASA 1968). Starbuck and Blake (1994) presented the design parameters for composite cylinders and analyzed the results of parametric studies of laminate stacking sequences with only hoop and axial layers. Messager (2001) presented an analytical eigenvalue buckling equation for imperfect laminated cylinders and compared the results with finite element analysis (FEA). Messager et al. (2002) later developed an analytical buckling shell model based on third-order shear deformable theory and compared the results with NLFEM and experimental results. Kim et al. (2010) and Jung et al. (2012) compared two analytical buckling pressure formulations, i.e., the ASME and NASA formulas, with NLFEM or experimental results. Rao Yarrapragada et al. (2012) used the Windenburg equation, which was developed for homogeneous materials, to predict the critical buckling pressure of composite shells with equivalent stiffness moduli, and compared the results with NLFEM. It is not surprising that a lot of studies on cylindrical shells made of steel or composite materials have also been made in the literature (Jones, 2010; Bai et al., 2013a; Bai et al., 2013b; Smith et al., 2013; Bai et al., 2014; Guz et al., 2014; Abdel-Nasser et al, 2015; Lee et al, 2016; Xiong et al., 2017). 
The aforementioned analytical formulas and numerical analyses to predict the buckling pressure for composite cylinders have sometimes shown large deviations in comparison with experimental results. This has motivated the development of a more reliable formula for predicting the collapse strength of composite cylinders without excessive computational cost.

This paper presents an analytical theoretical and experimental study of the buckling and collapse strength of composite cylindrical-shell structures under external pressure loads. Unstiffened filament-wound-type composite cylinder models, fabricated with $[ \pm \theta / 90]_{F W}$ winding angles, are tested to investigate the collapse characteristics under hydrostatic pressures, and the measured collapse pressures are analyzed to deduce a formula for the collapse-strength prediction of composite cylinders. The presented formula is also compared with those proposed by ASME (2007) and NASA (1968), and with FEA results.

2. Buckling pressure formulas for a composite cylinder

\subsection{ASME Code 2007 (RD-1172) formula}

ASME(2007) provides the following buckling pressure formula to estimate the allowable pressure for composite unstiffened cylinders under external hydrostatic pressure:

$$
P_{a}=\frac{(K D) 0.8531 \gamma E_{h f}^{3 / 4} E_{a t}^{1 / 4} t^{5 / 2}}{\left(1-v_{x} v_{y}\right)^{3 / 4} L\left(\frac{D_{o}}{2}\right)^{3 / 2} F}
$$

Where $P_{a}$ is the allowable pressure in psi. $D_{o}, L$, and $t$ are the diameter, length, and thickness (in) of the composite cylinder, respectively. $E_{a t}$ is the axial tensile modulus and $E_{h f}$ is the hoop flexural modulus. $v_{x}, v_{y}$ are the flexural Poisson's ratio in the axial and hoop direction, respectively. $F$ is the safety factor, and $K D$ is the knock-down factor, which is taken as 0.84. $\gamma$ is the reduction factor, based on the test results. If $Z_{p}$ is equal to or less than 100, the reduction factor is taken as $\gamma=1-0.001 Z_{p}$. If $Z_{p}$ is greater than 100 , $\gamma=0.9$ is taken, where $Z_{p}$ is given by

$$
Z_{p}=\frac{E_{h f}^{3 / 2} E_{a t}^{1 / 2}}{E_{a f}^{2}}\left(1-v_{x} v_{y}\right)^{1 / 2} \frac{L^{2}}{\left(\frac{D_{o}}{2} t\right)}
$$

Where $E_{a f}$ is the axial flexural modulus. The engineering constants, $E_{h f}, E_{a t}, E_{a f}, v_{x}$, and $v_{y}$, of the laminate are calculated given the material properties of each laminate, including $E_{1}, E_{2}, v_{12}, G_{12}$, and $t$. The $(A B D)$ matrix is computed from these values by applying the CLT (Jones 1999). This allows the calculation of the inverse matrix $(A B D)^{-1}$. With this process, the material properties are calculated based on the following formulas. 


$$
\begin{array}{r}
v_{x}=\frac{-\left(A B D^{-1}\right)_{5,4}}{\left(A B D^{-1}\right)_{4,4}}, v_{y}=\frac{-\left(A B D^{-1}\right)_{5,4}}{\left(A B D^{-1}\right)_{5,5}}, E_{a f}=\frac{12}{t^{3}\left(A B D^{-1}\right)_{4,4}}, E_{h f}=\frac{12}{t^{3}\left(A B D^{-1}\right)_{5,5}} \\
E_{a t}=\frac{A_{11} A_{22}-A_{12}^{2}}{A_{22} t}
\end{array}
$$

\subsection{NASA SP-8700 formula}

NASA SP-8700 (NASA, 1968) provides the following buckling pressure formula of cylindrical shells:

$$
P_{a}=\frac{R}{F\left[n^{2}+\frac{1}{2}\left(\frac{m \pi R}{L}\right)^{2}\right]} \frac{\operatorname{det}\left[\begin{array}{lll}
C_{11} & C_{12} & C_{13} \\
C_{21} & C_{22} & C_{23} \\
C_{31} & C_{32} & C_{33}
\end{array}\right]}{\operatorname{det}\left[\begin{array}{ll}
C_{11} & C_{12} \\
C_{21} & C_{22}
\end{array}\right]}
$$

where

$$
\begin{aligned}
& C_{11}=A_{11}\left(\frac{m \pi}{L}\right)^{2}+A_{66}\left(\frac{n}{R}\right)^{2}, C_{22}=A_{22}\left(\frac{n}{R}\right)^{2}+A_{66}\left(\frac{m \pi}{L}\right)^{2}, \\
& C_{33}=D_{11}\left(\frac{m \pi}{L}\right)^{4}+2\left(D_{12}+2 D_{66}\right)\left(\frac{m \pi}{L}\right)^{2}\left(\frac{n}{R}\right)^{2}+D_{22}\left(\frac{n}{R}\right)^{4}+\frac{A_{22}}{R^{2}}+\frac{2 B_{22}}{R^{2}}\left(\frac{n}{R}\right)^{2}+\frac{2 B_{12}}{R^{2}}\left(\frac{m \pi}{L}\right)^{2}, \\
& C_{12}=C_{21}=\left(A_{12}+A_{66}\right)\left(\frac{m \pi}{L}\right)\left(\frac{n}{R}\right), \\
& C_{13}=C_{31}=\frac{A_{12}}{R}\left(\frac{m \pi}{L}\right)+B_{11}\left(\frac{m \pi}{L}\right)^{3}+\left(B_{12}+2 B_{66}\right)\left(\frac{m \pi}{L}\right)\left(\frac{n}{R}\right)^{2}, \\
& C_{23}=C_{32}=\left(B_{12}+2 B_{66}\right)\left(\frac{m \pi}{L}\right)^{2}\left(\frac{n}{R}\right)+\frac{A_{22}}{R}\left(\frac{n}{R}\right)+B_{22}\left(\frac{n}{R}\right)^{3},
\end{aligned}
$$

Where $R$ and $L$ are the radius and length of the composite cylinder. $F$ is the safety factor. $m$ and $n$ are integer numbers necessary to produce the correct minimum buckling pressure.

Table 1 Material properties of T700 composite used in the test models

\begin{tabular}{c|c|c}
\hline Property & Direction & Value \\
\hline \multirow{2}{*}{ Elastic modulus $(\mathrm{GPa})$} & Fiber & 121.00 \\
\cline { 2 - 3 } & Matrix & 8.60 \\
\hline \multirow{2}{*}{ Shear modulus $(\mathrm{GPa})$} & In-plane & 3.35 \\
\cline { 2 - 3 } & Transverse & 2.68 \\
\hline \multirow{2}{*}{ Poisson's ratio } & In-plane & 0.253 \\
\cline { 2 - 3 } & Transverse & 0.421 \\
\hline
\end{tabular}




\begin{tabular}{c|c|c}
\hline \multirow{2}{*}{ Tensile strength(MPa) } & In-plane & 2060 \\
\cline { 2 - 3 } & Transverse & 32 \\
\hline \multirow{2}{*}{ Shear strength(MPa) } & In-plane & 45 \\
\cline { 2 - 3 } & Transverse & 64 \\
\hline
\end{tabular}

\section{Hydrostatic buckling experiments}

In this study, a series of hydrostatic buckling tests are undertaken on composite cylinder models. A filament-wound technique was used to fabricate the test models. The winding orientation angles were $[ \pm 30 / 90]_{\mathrm{FW}},[ \pm 45 / 90]_{\mathrm{FW}},[ \pm 60 / 90]_{\mathrm{FW}}$, and $[ \pm 60]_{\mathrm{FW}}$. The composite material was carbon fiber T700, and its mechanical properties are indicated in Table 1.

A total of 20 composite cylinder models were tested to measure the collapse pressure. Of these model test results, 12 using [FWT8 $\theta / 90$ ] were obtained from a previous study (Moon et al. 2010), and the other 8 models using [FWT6 45/90], [FWT10 45/90], and [FWT8 60] were newly tested in this study. Table 2 indicates the dimensions of the test models including length, radius, and thickness, and the measured collapse pressures.

Table 2 Dimensions and collapse pressures of the composite cylinder models for the hydrostatic pressure tests

\begin{tabular}{cccccc}
\hline Model & $\begin{array}{c}\text { Length } \\
(\mathrm{mm})\end{array}$ & $\begin{array}{c}\text { Radius } \\
\text { inner } \\
(\mathrm{mm})\end{array}$ & $\begin{array}{c}\text { Thickness } \\
(\mathrm{mm})\end{array}$ & $\begin{array}{c}\text { Hoop } \\
\text { thickness } \\
(\mathrm{mm})\end{array}$ & $\begin{array}{c}\text { Collapse } \\
\text { pressure } \\
(\mathrm{MPa})\end{array}$ \\
\hline FWT8 30/90-1 & 686 & 150 & 8.01 & 1.43 & 4.30 \\
FWT8 30/90-2 & 687 & 150 & 8.00 & 1.36 & 4.40 \\
FWT8 30/90-3 & 687 & 150 & 8.01 & 1.61 & 3.80 \\
FWT8 30/90-4 & 6887 & 150 & 8.01 & 1.52 & 4.01 \\
FWT8 45/90-1 & 695 & 150 & 8.12 & 0.97 & 5.80 \\
FWT8 45/90-2 & 695 & 150 & 8.13 & 1.04 & 5.62 \\
FWT8 45/90-3 & 695 & 150 & 8.14 & 0.97 & 5.47 \\
FWT8 45/90-4 & 695 & 150 & 8.25 & 0.99 & 5.45 \\
FWT8 60/90-1 & 695 & 150 & 7.80 & 0.99 & 7.18 \\
FWT8 60/90-2 & 695 & 150 & 7.83 & 0.95 & 6.97 \\
FWT8 60/90-3 & 695 & 150 & 7.79 & 1.03 & 7.33 \\
FWT8 60/90-4 & 695 & 150 & 7.98 & 1.05 & 7.14 \\
FWT6 45/90-1 & 695 & 150 & 6.05 & 0.62 & 3.09 \\
FWT6 45/90-2 & 694 & 150 & 6.18 & 0.70 & 3.27 \\
FWT6 45/90-3 & 693 & 150 & 6.09 & 0.66 & 3.23 \\
FWT10 45/90-1 & 693 & 150 & 10.41 & 1.01 & 11.64 \\
FWT10 45/90-2 & 693 & 150 & 10.37 & 1.05 & 11.80 \\
FWT10 45/90-3 & 694 & 150 & 10.61 & 1.09 & 11.87 \\
FWT8 60-1 & 686 & 150 & 8.24 & 0.0 & 8.04 \\
FWT8 60-2 & 686 & 150 & 7.97 & 0.0 & 7.36 \\
\hline
\end{tabular}


Figures 1 and 2 show a schematic of the hydrostatic test. Figure 3 shows photographs of the composite cylinder specimens used in the experiment. The model cylinder specimen is attached to the pressure chamber using the steel flange on the pressure chamber (Cho et al. 2009). Figure 4 shows the stacking sequence of the composite cylinder shell. Figure 5 and 6 show the typical failure modes and local buckling mode shapes of the composite shells. It has been concluded that the test specimens initially began to collapse usually in the buckling mode shape $(3,1)$, three waves in the circumferential direction and one long wave in the axial direction, and finally failed in form of the material failure. However, the local deflections have been observed in some test results. It has been thought that these local deflections were attributed to the initial material and geometrical imperfections (Moon et al. 2010).

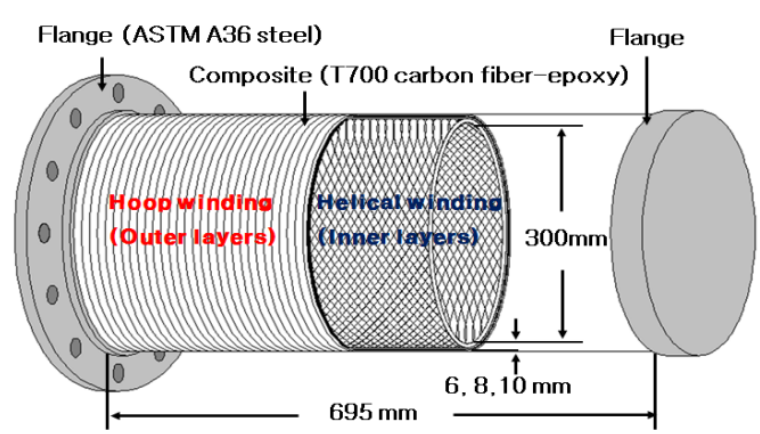

(a) Composite cylinder

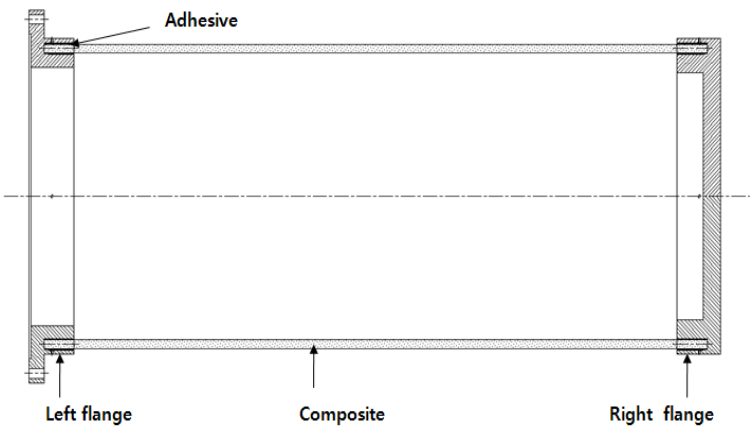

(b) Cylinder bound to the end flanges

Figure 1. Schematic of a filament-wound composite cylinder with flanges.

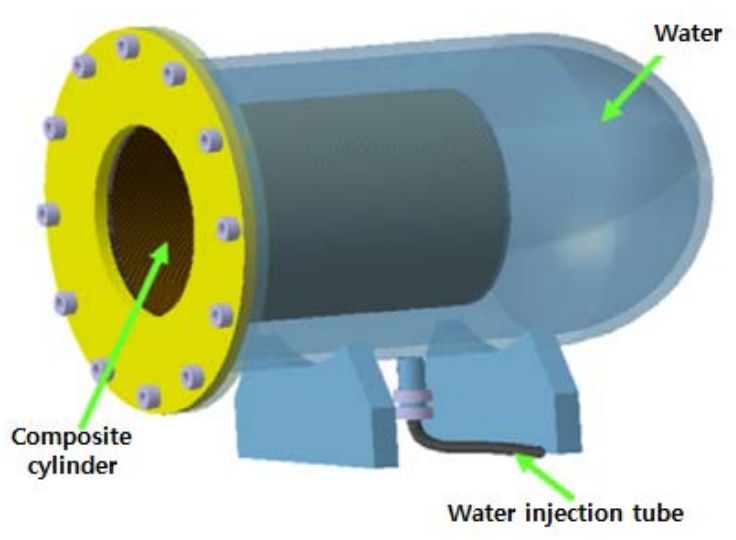

(a) Hydrostatic pressure chamber

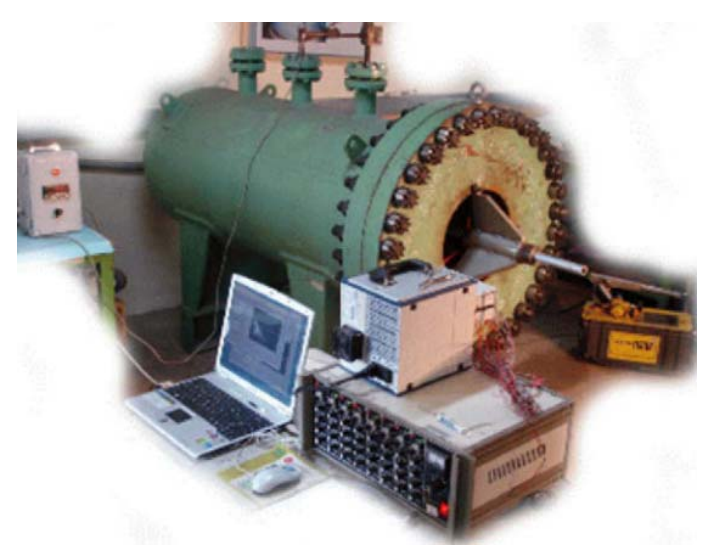

(b) Experimental set-up

Figure 2. Schematic of the hydrostatic test.
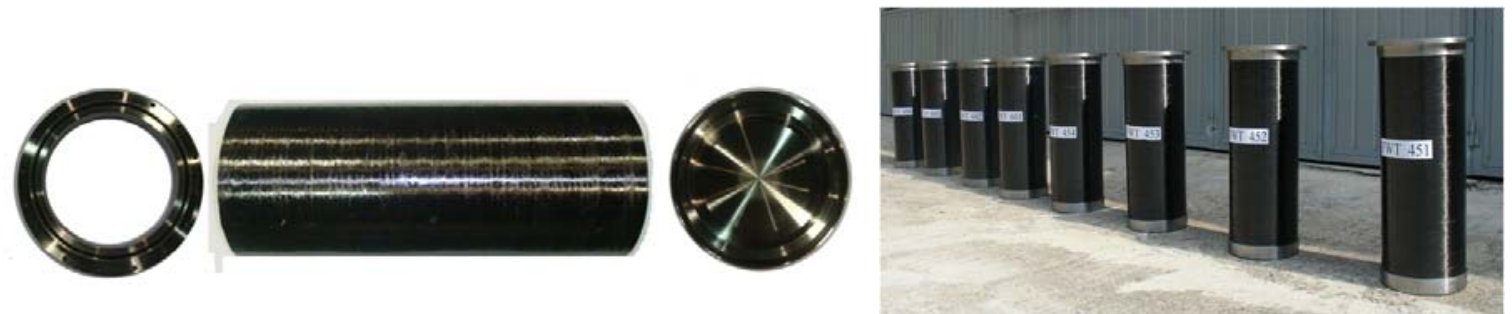
Figure 3. Composite cylinder specimens for the hydrostatic pressure buckling test.

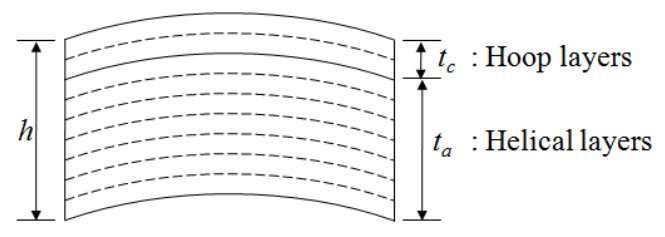

Figure 4. Stacking sequence of the composite shell.

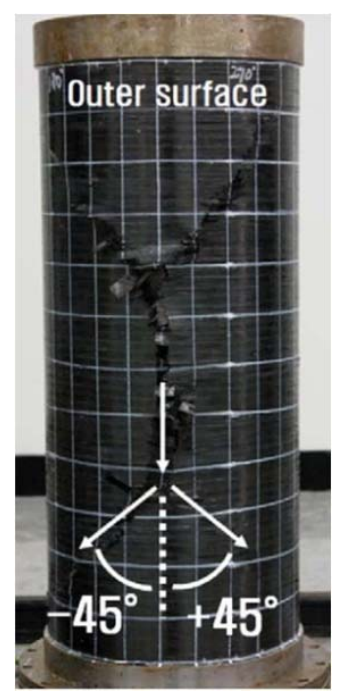

(a) FWT 45

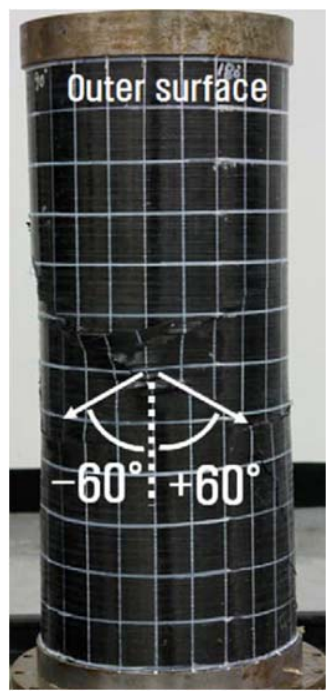

(b) FWT 60

Figure 5. Typical final failure modes of the composite shells: $[ \pm 45 / 90] \mathrm{FW}$ and $[ \pm 60 / 90] \mathrm{FW}$

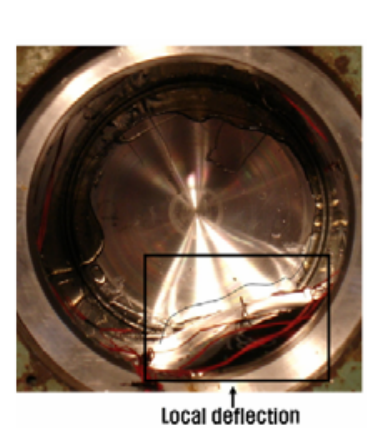

(a) FWT 30

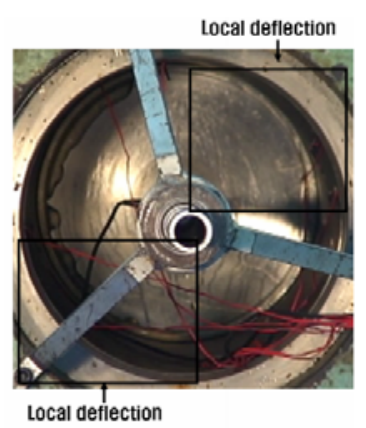

(b) FWT 60

Figure 6. Typical local buckling modes of the composite shells: $[ \pm 30 / 90]_{\mathrm{FW}}$ and $[ \pm 60 / 90]_{\mathrm{FW}}$

4. Design formula for composite cylinders

To consider simultaneously the elastic buckling mode and the material failure mode, an analytical design formula is proposed to calculate the collapse pressure of filament-wound, 
unstiffened composite cylinders. The proposed ultimate-strength design formula is derived from the measured collapse pressures of the composite cylinder models, and has the form of the Merchant-Rankine equation, which is composed of the elastic buckling pressure and material failure pressure for composite cylinders, as follows:

$$
\left(\frac{p_{c r}}{p_{m}}\right)^{\alpha}+\left(\frac{p_{c r}}{p_{f}}\right)^{\beta}=1 \text { with } \alpha=-2, \beta=-2
$$

where $p_{c r}, p_{m}$, and $p_{f}$ are respectively the collapse pressure, elastic buckling pressure, and material failure pressure of the composite cylinders.

\subsection{Elastic buckling pressure for composite cylinder}

The proposed analytical model for the elastic buckling of a composite cylinder considers the mean surface of the cylinder, but neglects the transverse shear effects. The presented linear buckling analysis is based on the principles of the Messager (2001) model, and is adapted to a simple and geometrically perfect case.

The composite cylindrical shell has a length $L$, radius $R$, and wall thickness $h$. As shown in Fig. 7, the $x, y$, and $z$ coordinates and the corresponding $u, v$ and $w$ displacements are in the axial, circumferential, and radial directions, respectively, with respect to the cylindrical mean surface. Because the composite cylinders are fabricated with the filament winding technique, the $k$-th composite layer is assumed to be orthotropic and cross-ply, i.e. made up of equal amounts of fibers evenly distributed through its thickness in the $\pm \theta_{k}$ directions with respect to the cylinder axis.

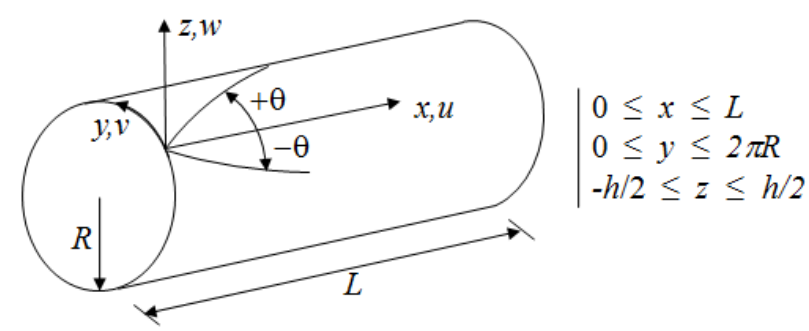

Figure 7. Geometry of the cylindrical shell.

Equilibrium of the internal and external forces acting in the $x, y$, and $z$ directions upon a shell element is achieved if the following three partial differential equations are satisfied:

$$
\frac{\partial N_{x}}{\partial x}+\frac{\partial N_{x y}}{\partial y}=0, \frac{\partial N_{x y}}{\partial x}+\frac{\partial N_{y}}{\partial y}=0, \frac{\partial^{2} M_{x}}{\partial x^{2}}+2 \frac{\partial^{2} M_{x y}}{\partial x \partial y}+\frac{\partial^{2} M_{y}}{\partial y^{2}}-\frac{1}{R} N_{y}-\hat{N}_{x} \frac{\partial^{2} w}{\partial x^{2}}-\hat{N}_{y} \frac{\partial^{2} w}{\partial y^{2}}=0
$$


Where $\hat{N}_{x}, \hat{N}_{y}$ are the membrane forces and are given under external pressure $p$ as follows, and the shear membrane force $\hat{N}_{x y}$ is set to zero because buckling under torsion is not considered.

$$
\hat{N}_{x}=\frac{p R}{2}, \quad \hat{N}_{y}=p R
$$

The composite cylinders are assumed to be simply supported at both ends. The chosen displacement approximation functions satisfying these boundary conditions are:

$$
\left\{\begin{array} { l } 
{ u = u ( x , y ) = a _ { u } \operatorname { c o s } ( \overline { m } x ) \operatorname { c o s } ( \overline { n } y ) } \\
{ v = v ( x , y ) = a _ { v } \operatorname { s i n } ( \overline { m } x ) \operatorname { s i n } ( \overline { n } y ) } \\
{ w = w ( x , y ) = a _ { w } \operatorname { s i n } ( \overline { m } x ) \operatorname { c o s } ( \overline { n } y ) }
\end{array} \text { with } \left\{\begin{array}{l}
\bar{m}=\frac{\pi m}{L} \\
\bar{n}=\frac{n}{R}
\end{array}\right.\right.
$$

where $m$ and $n$ are the numbers of longitudinal and circumferential half waves, respectively, representing the buckling mode.

Substituting equations (8) and (9) into the governing equation (7), the integration of the governing equation then leads to the eigenvalue problem in the following simple form, in the same way as Messager (2001):

$$
([K]+p L[L])\left\{\begin{array}{l}
a_{u} \\
a_{v} \\
a_{w}
\end{array}\right\}=\left\{\begin{array}{l}
0 \\
0 \\
0
\end{array}\right\}
$$

where $[K]$ and $[L]$ are $3 \times 3$ matrixes, and $K_{i j}$ and $L_{i j}$ are reduced as follows:

$$
\begin{aligned}
& K_{11}=A_{11} \bar{m}^{2}+A_{66} \bar{n}^{2}, K_{12}=K_{21}=\left(A_{12}+A_{66}\right) \bar{m} \bar{n}, \\
& K_{13}=K_{31}=\frac{A_{12}}{R} \bar{m}+B_{11} \bar{m}^{3}+\left(B_{12}+2 B_{66}\right) \bar{m} \bar{n}^{2}, \\
& K_{22}=A_{22} \bar{n}^{2}+A_{66} \bar{m}^{2}, K_{23}=K_{32}=\left(B_{12}+2 B_{66}\right) \bar{m}^{2} \bar{n}+\frac{A_{22}}{R} \bar{n}+B_{22} \bar{n}^{3}, \\
& K_{33}=D_{11} \bar{m}^{4}+2\left(D_{12}+2 D_{66}\right) \bar{m}^{2} \bar{n}^{2}+D_{22} \bar{n}^{4}+\frac{A_{22}}{R^{2}}+\frac{2 B_{12}}{R} \bar{m}^{2}+\frac{2 B_{22}}{R} \bar{n}^{2}, \\
& L_{11}=L_{12}=L_{13}=L_{21}=L_{22}=L_{23}=L_{31}=L_{32}=0, L_{33}=-\frac{R}{2} \bar{m}^{2}-R \bar{n}^{2}
\end{aligned}
$$

where $A_{i j}, B_{i j}$, and $D_{i j}$ are defined as in the CLT. The terms in Eq. (11) are derived for a geometrically perfect composite cylinder model, and thus have simpler forms than the model of Messager (2001), which accounts for imperfections. The critical external pressure corresponds to the lowest $p$ value satisfying Eq. (10), and is the elastic buckling pressure $p_{m}$ for the composite cylinder. 
4.2 Material failure pressure for composite cylinder

The composite cylinder deforms under hydrostatic external pressure and its deformation progresses until it collapses, leading to failure of the material. During its deformation the internal forces act upon the fibers in the principal directions. The fiber materials begin to fail at the significant pressure when the fiber stresses reach the tensile strength $X_{T}$, compressive strength $Y_{T}$, or the transverse or shear strength $S_{T}$ with respect to the fiber directions. The composite cylinders are considered to collapse at the moment this occurs.

The fiber stresses can be calculated using CLT under an applied load $p$, and are separated into the fiber directional stress $\sigma_{1}$, in-plane transversal stress $\sigma_{2}$, and in-plane shear stress $\tau_{12}$ components in each layer. The ratios of these stresses to the tensile, compressive, and shear strengths $X_{T}, Y_{T}, S_{T}$ can be calculated and the maximum failure index (FI) is then determined as follows.

$$
\text { FI = Max. of }\left\{\frac{\sigma_{1}}{X_{T}}, \frac{\left|\sigma_{1}\right|}{X_{C}}, \frac{\sigma_{2}}{Y_{T}}, \frac{\left|\sigma_{2}\right|}{Y_{C}}, \frac{\left|\tau_{12}\right|}{S_{T}}\right\}
$$

Therefore, the material failure pressure $p_{f}$ can be obtained from Eq. (13) by dividing the applied load $p$ through FI as follows:

$$
p_{f}=\frac{p}{F I}
$$

4.3 Collapse pressure for composite cylinders and a reduction factor

Substituting the elastic buckling pressures $p_{m}$ and the material failure pressures $p_{f}$ into Eq. (6), the analytical collapse pressures $p_{c r}^{i}$ for the composite cylinders can be computed. Compared with the experimental collapse pressures $p_{c r}^{\text {exp }}$, the analytical collapse pressures $p_{c r}^{i}$ are calculated to be larger. We attribute this to imperfections in the manufacture of the composite cylinders. The effect of these imperfections must be taken into account to deduce the correct collapse pressure of real composite cylinders. Thus, the reduction factor $\gamma$ is introduced, which is empirically defined as follows.

$$
\gamma=1-0.3 \exp \left\{-0.1\left(20 \frac{p_{m}}{p_{f}}-13.9\right)\right\}
$$

The appropriate reduction factor is determined by analyzing the experimental results for the composite cylinders obtained in Section 3. Finally, the predicted collapse pressures $p_{c r}^{p r d}$ are expressed as follows:

$$
p_{c r}^{p r d}=\gamma p_{c r}^{i}
$$


Finally, the collapse pressures for the filament-wound composite cylinder models in Section 3 can be calculated analytically from the above equation (15), and compared with the experimental collapse pressures.

\section{Results and discussion}

\subsection{Buckling formulas of ASME and NASA}

Table 3 shows the buckling pressures calculated from the ASME and NASA SP-8700 buckling formulas, and compares them with the experimental collapse pressures measured using the composite cylinder models.

For the ASME 2007 formula, the safety factors of the buckling pressures values, which are defined relative to the experimental collapse pressures, are within the range 1.43-3.53. The safety factors of the NASA SP-8700 formula are in the range 1.14-1.50, i.e., they are generally lower than for the ASME formula. This implies that the former method is more reliable than the latter. Nonetheless, the NASA formula still produces errors ranging from $14 \%$ to $50 \%$, which can be regarded as comparatively large in the context of composite cylinder design.

Table 3 Buckling pressures from ASME and NASA formulas compared with experiment results

\begin{tabular}{c|c|c|c|c|c}
\hline & \multicolumn{2}{|c|}{ ASME 2007 } & \multicolumn{2}{|c|}{$\begin{array}{c}\text { NASA SP- } \\
8007\end{array}$} & $\begin{array}{c}\text { Experiment } \\
\left(p_{c r}^{\text {exp }}\right)\end{array}$ \\
\cline { 2 - 5 } & MPa & $\begin{array}{c}\text { Safety } \\
\text { factor }\end{array}$ & MPa & $\begin{array}{c}\text { Safety } \\
\text { factor }\end{array}$ & \\
\hline FWT8 30/90-1 & 2.68 & 1.61 & 3.40 & 1.26 & 4.30 \\
FWT8 30/90-2 & 2.67 & 1.65 & 3.41 & 1.29 & 4.40 \\
FWT8 30/90-3 & 2.67 & 1.43 & 3.34 & 1.14 & 3.80 \\
FWT8 30/90-4 & 2.67 & 1.50 & 3.37 & 1.19 & 4.01 \\
FWT8 45/90-1 & 2.56 & 2.27 & 4.58 & 1.27 & 5.80 \\
FWT8 45/90-2 & 2.58 & 2.18 & 4.54 & 1.24 & 5.62 \\
FWT8 45/90-3 & 2.57 & 2.13 & 4.60 & 1.19 & 5.47 \\
FWT8 45/90-4 & 2.66 & 2.05 & 4.72 & 1.15 & 5.45 \\
FWT8 60/90-1 & 2.77 & 2.59 & 4.92 & 1.46 & 7.18 \\
FWT8 60/90-2 & 2.78 & 2.51 & 4.99 & 1.40 & 6.97 \\
FWT8 60/90-3 & 2.78 & 2.64 & 4.88 & 1.50 & 7.33 \\
FWT8 60/90-4 & 2.94 & 2.43 & 5.18 & 1.38 & 7.14 \\
FWT6 45/90-1 & 1.22 & 2.54 & 2.48 & 1.25 & 3.09 \\
FWT6 45/90-2 & 1.30 & 2.52 & 2.64 & 1.24 & 3.27 \\
FWT6 45/90-3 & 1.25 & 2.59 & 2.53 & 1.28 & 3.23 \\
FWT10 45/90-1 & 4.61 & 2.53 & 8.01 & 1.45 & 11.64 \\
FWT10 45/90-2 & 4.59 & 2.57 & 7.89 & 1.49 & 11.80 \\
FWT10 45/90-3 & 4.86 & 2.44 & 8.30 & 1.43 & 11.87 \\
FWT8 60-1 & 2.28 & 3.53 & 6.17 & 1.30 & 8.04 \\
\hline
\end{tabular}




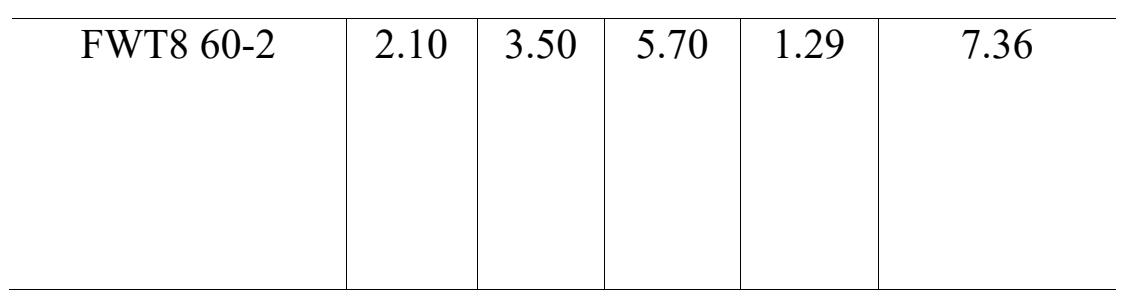

Both of the above-mentioned design formulas are based on the elastic buckling pressures of the composite cylinders. The elastic buckling mode dominates for very thin composite cylinders. However, the material failure mode of composite cylinders is known to affect the collapse pressure of moderately thick composite cylinders. Thus, we propose that the calculated errors arise from the mode interactions between the elastic buckling mode and the material failure mode. Therefore, to account for the interaction between the two modes, a new design formula is needed, which should be able to predict more accurate collapse pressures for the composite cylinders while remaining rapidly solvable.

\subsection{Proposed design formula}

The collapse pressures predicted by the newly proposed strength design formula are compared with the experimental results and FEA results from MSC/NASTRAN in Table 4.

The elastic buckling pressures in Table 4 are identical to the buckling pressures of the NASA SP-8700 formula in Table 3. This reflects the fact that the NASA formula is constructed on the basis of elastic buckling theory for the composite cylinder. The safety factors $p_{c r}^{\exp } / p_{c r}^{p r d}$, i.e., the ratios of the experimental collapse pressures to the predicted collapse pressures for the cylinder model, are presented to assess the validity of the proposed method of calculating collapse pressures for composite cylinders. The calculated safety factors fall within the range $0.95-1.26$, where the average value is 1.10 , and the standard deviation is 0.0092 . Thus, the coefficient of variation $(\mathrm{COV})$ is calculated as $0.83 \%$. The standard error (SE) is calculated as 0.0264 using the following equation.

$$
S E=\left[\frac{\sum\left(\frac{p_{c r}^{\text {prd }}}{p_{c r}^{\exp }}-1\right)^{2}}{N(N-1)}\right]^{1 / 2}
$$

where $N$ is taken as 20 .

Table 4 Buckling pressures from the proposed method compared with elastic buckling, FEA, and experiments

\begin{tabular}{|c|c|c|c|c|c|c|c|}
\hline \multirow{2}{*}{ Model } & \multicolumn{2}{|c|}{$\begin{array}{l}\text { Elastic buckling } \\
\qquad p_{m}\end{array}$} & \multicolumn{2}{|c|}{$\begin{array}{l}\text { Proposed method } \\
\qquad p_{c r}^{p r d}\end{array}$} & \multicolumn{2}{|c|}{$\begin{array}{c}\text { FEA(NASTRAN) } \\
p_{c r}^{f e a}\end{array}$} & \multirow{2}{*}{$\begin{array}{c}\text { Experiment } \\
p_{c r}^{\exp } \\
(\mathrm{MPa})\end{array}$} \\
\hline & $\mathrm{MPa}$ & $\begin{array}{l}\text { Safety } \\
\text { factor }\end{array}$ & $\mathrm{MPa}$ & $\begin{array}{l}\text { Safety } \\
\text { factor }\end{array}$ & $\mathrm{MPa}$ & $\begin{array}{l}\text { Safety } \\
\text { factor }\end{array}$ & \\
\hline
\end{tabular}




\begin{tabular}{c|l|l|l|l|l|l|l}
\hline FWT8 30/90-1 & 3.400 & 1.26 & 3.826 & 1.12 & 4.351 & 0.99 & 4.30 \\
FWT8 30/90-2 & 3.412 & 1.29 & 3.835 & 1.15 & 4.367 & 1.01 & 4.40 \\
FWT8 30/90-3 & 3.339 & 1.14 & 3.771 & 1.01 & 4.288 & 0.89 & 3.80 \\
FWT8 30/90-4 & 3.369 & 1.19 & 3.798 & 1.06 & 4.323 & 0.93 & 4.01 \\
FWT8 45/90-1 & 4.578 & 1.27 & 5.601 & 1.04 & 5.498 & 1.05 & 5.80 \\
FWT8 45/90-2 & 4.537 & 1.24 & 5.553 & 1.01 & 5.636 & 1.00 & 5.62 \\
FWT8 45/90-3 & 4.602 & 1.19 & 5.629 & 0.97 & 5.634 & 0.97 & 5.47 \\
FWT8 45/90-4 & 4.720 & 1.15 & 5.767 & 0.95 & 5.863 & 0.93 & 5.45 \\
FWT8 60/90-1 & 4.919 & 1.46 & 5.941 & 1.21 & 7.034 & 1.02 & 7.18 \\
FWT8 60/90-2 & 4.985 & 1.40 & 6.023 & 1.16 & 7.095 & 0.98 & 6.97 \\
FWT8 60/90-3 & 4.884 & 1.50 & 5.896 & 1.24 & 7.034 & 1.04 & 7.33 \\
FWT8 60/90-4 & 5.181 & 1.38 & 6.233 & 1.15 & 7.504 & 0.95 & 7.14 \\
FWT6 45/90-1 & 2.479 & 1.25 & 3.087 & 1.00 & 2.617 & 1.18 & 3.09 \\
FWT6 45/90-2 & 2.638 & 1.24 & 3.281 & 1.00 & 2.761 & 1.18 & 3.27 \\
FWT6 45/90-3 & 2.527 & 1.28 & 3.145 & 1.03 & 2.663 & 1.21 & 3.23 \\
FWT10 45/90-1 & 8.014 & 1.45 & 9.511 & 1.22 & 10.63 & 1.09 & 11.64 \\
FWT10 45/90-2 & 7.893 & 1.49 & 9.376 & 1.26 & 10.61 & 1.11 & 11.80 \\
FWT10 45/90-3 & 8.296 & 1.43 & 9.824 & 1.21 & 11.23 & 1.06 & 11.87 \\
FWT8 60-1 & 6.173 & 1.30 & 7.059 & 1.14 & 7.361 & 1.09 & 8.04 \\
FWT8 60-2 & 5.700 & 1.29 & 6.879 & 1.07 & 6.729 & 1.09 & 7.36 \\
\hline
\end{tabular}

From these results it is concluded that the proposed method can accurately predict the collapse pressures for composite cylinders.

For further comparison, the FE buckling pressures $p_{c r}^{\text {fea }}$ have been obtained for the experimental models using MSC/NASTRAN. For this method the safety factors fall within the range $0.89-1.21$, where the average value is 1.04 , the standard deviation is 0.0078 , and the $\mathrm{COV}$ is $0.75 \%$. The SE is 0.0199 , calculated from the factor $p_{c r}^{\text {fea }} / p_{c r}^{\exp }$.

\subsection{Finite element analysis}

The test specimens are analyzed through FEA. MSC/NASTRAN has been used to predict the buckling behavior of the composite cylinders with four-node element CQUAD4. The mesh sizes and numbers in the axial and tangential direction are chosen to represent well the cylinder collapse pressures in the test specimens.

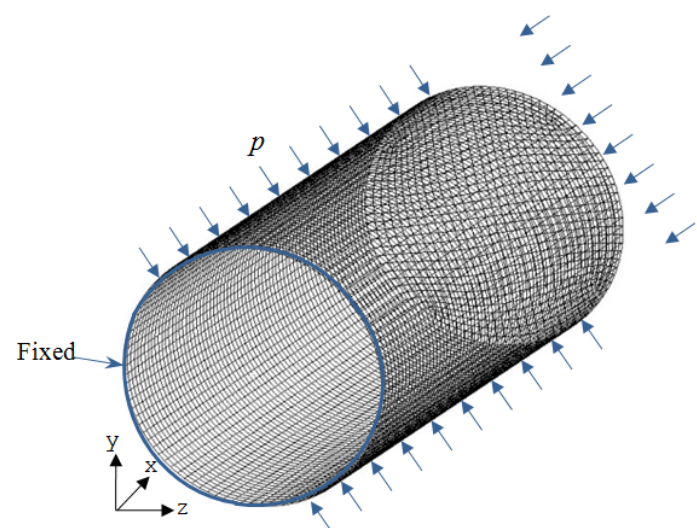

Figure 8. Typical FE model of the composite cylinders 
As the number of layer for the composite shell, a total of five layers are assumed on the NLFEM to save the calculation time. It has been verified that the proposed, simple idealization models gave the almost same bucking load as the full model that take into consideration all layers. Initial geometric imperfections of the cylinders are not considered in FEA. Nonlinear static analysis, SOL 106, is performed with LGDIS=1, Stiffness matrix update $=$ AUTO options. Total loads and incremental loads of the NLFEM are selected carefully for the convergence of the solution in MSC/NASTRAN.

The buckling modes of all the cylinders have three waves in the circumferential direction and one long wave in the axial direction, as shown below:

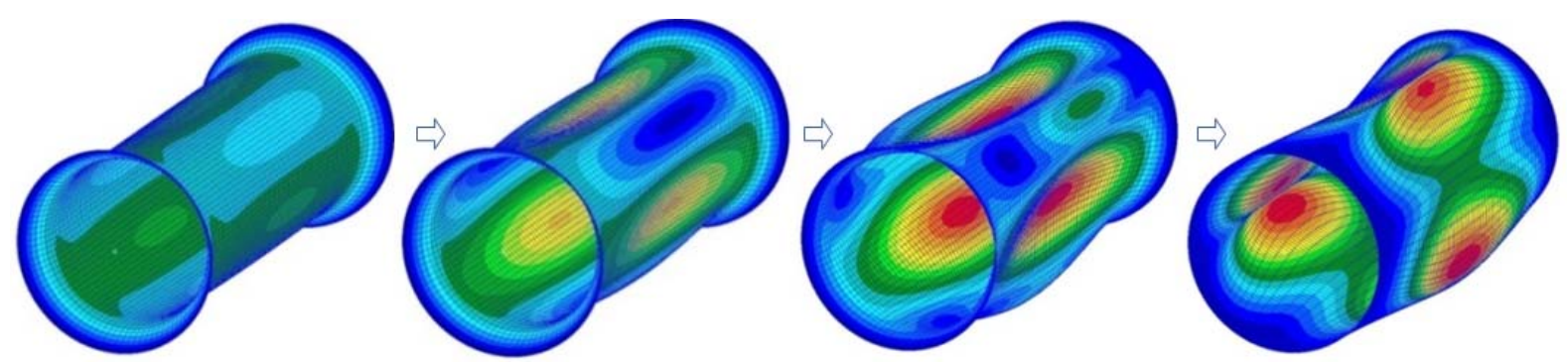

Figure 9. Typical shapes during the failure process of $[ \pm 30 / 90]_{\mathrm{FW}}$ in NLFEA

Comparing the FEA and experimental results, it is shown that the finite element analysis done with first-order shear deformable shell elements reasonably predicted the buckling pressure of moderately thick-walled filament-wound composite cylinders under external pressure

\subsection{Verification of the proposed design formula}

The proposed design formula for predicting the collapse pressure of composite cylinders was subjected to verification. The collapse pressures from the new design formula, $p_{c r}^{p r d}$, were compared with those from FEA, $p_{c r}^{\text {fea }}$, for filament-wound composite cylinders of 695 $\mathrm{mm}$ length, $150 \mathrm{~mm}$ radius, and thicknesses of $6 \mathrm{~mm}, 8 \mathrm{~mm}, 10 \mathrm{~mm}$, and $12 \mathrm{~mm}$. The ratio of the hoop thickness $t_{c}$ to wall thickness $h$ (Fig. 3) was set as 0.1 for all cylinders. The calculations assumed the same constitutive material as in the experiments. The predicted pressures from the proposed design formula are listed in Table 5 with respect to the helical angle $\theta$. The FEA results were obtained using MSC/NASTRAN.

Table 5 Predicted collapse pressures from the proposed method compared with FEA results

\begin{tabular}{c|c|c|c|c|c|c|c|c|c|c|c|c}
\hline Helical & \multicolumn{2}{|c|}{$h=6 \mathrm{~mm}$} & \multicolumn{3}{c|}{$h=8 \mathrm{~mm}$} & \multicolumn{3}{c|}{$h=10 \mathrm{~mm}$} & \multicolumn{2}{c}{$h=12 \mathrm{~mm}$} \\
\cline { 2 - 5 } $\begin{array}{c}\text { angle }(\theta) \\
(\text { degree })\end{array}$ & $p_{c r}^{\text {fea }}$ & $p_{c r}^{\text {prd }}$ & Safety & $p_{c r}^{\text {fea }}$ & $p_{c r}^{\text {prd }}$ & Safety & $p_{c r}^{\text {fea }}$ & $p_{c r}^{\text {prd }}$ & Safety & $p_{c r}^{\text {fea }}$ & $p_{c r}^{\text {prd }}$ & Safety \\
(MPa & $(\mathrm{MPa})$ & factor & $(\mathrm{MPa})$ & $(\mathrm{MPa})$ & factor & $(\mathrm{MPa})$ & $(\mathrm{MPa})$ & factor & $(\mathrm{MPa})$ & $(\mathrm{MPa})$ & factor \\
\hline
\end{tabular}




\begin{tabular}{c|c|c|c|c|c|c|c|c|c|c|c|c}
\hline 5 & 1.829 & 2.009 & 0.91 & 3.363 & 3.610 & 0.93 & 5.660 & 6.195 & 0.91 & 8.728 & 9.849 & 0.89 \\
10 & 1.962 & 1.996 & 0.98 & 3.802 & 3.763 & 1.01 & 6.217 & 6.407 & 0.97 & 9.470 & 10.14 & 0.93 \\
15 & 2.047 & 2.036 & 1.01 & 4.256 & 3.823 & 1.11 & 6.820 & 6.505 & 1.05 & 10.28 & 10.30 & 1.00 \\
20 & 2.128 & 1.986 & 1.07 & 4.513 & 3.786 & 1.19 & 7.173 & 6.515 & 1.10 & 10.77 & 10.41 & 1.03 \\
25 & 2.243 & 1.913 & 1.17 & 4.575 & 3.782 & 1.21 & 7.302 & 6.658 & 1.10 & 11.00 & 10.80 & 1.02 \\
30 & 2.461 & 1.924 & 1.28 & 4.525 & 3.995 & 1.13 & 7.451 & 7.218 & 1.03 & 11.42 & 11.89 & 0.96 \\
35 & 2.465 & 2.111 & 1.17 & 4.539 & 4.574 & 0.99 & 7.695 & 8.406 & 0.92 & 12.09 & 13.31 & 0.91 \\
40 & 2.453 & 2.505 & 0.98 & 4.819 & 5.600 & 0.86 & 8.395 & 8.849 & 0.95 & 13.57 & 12.54 & 1.08 \\
45 & 2.565 & 3.013 & 0.85 & 5.266 & 5.588 & 0.94 & 9.614 & 8.701 & 1.10 & 15.56 & 12.92 & 1.20 \\
50 & 2.787 & 3.077 & 0.91 & 5.902 & 5.633 & 1.05 & 11.06 & 9.349 & 1.18 & 17.52 & 14.40 & 1.22 \\
55 & 3.089 & 3.181 & 0.97 & 6.661 & 5.989 & 1.11 & 12.19 & 10.07 & 1.21 & 16.96 & 15.65 & 1.08 \\
60 & 3.417 & 3.412 & 1.00 & 7.445 & 6.444 & 1.16 & 12.18 & 10.87 & 1.12 & 17.81 & 16.94 & 1.05 \\
65 & 3.757 & 3.641 & 1.03 & 8.213 & 6.879 & 1.19 & 12.33 & 11.63 & 1.06 & 17.58 & 18.15 & 0.97 \\
70 & 4.079 & 3.834 & 1.06 & 8.348 & 7.259 & 1.15 & 12.61 & 12.29 & 1.03 & 17.96 & 17.78 & 1.01 \\
\hline
\end{tabular}

Table 5 shows that the safety factors $\left(p_{c r}^{\text {fea }} / p_{c r}^{\text {prd }}\right)$ of the proposed design formula are in the range of $0.85-1.28$ for $h=6 \mathrm{~mm}, 0.86-1.21$ for $h=8 \mathrm{~mm}, 0.91-1.21$ for $h=10 \mathrm{~mm}$, and $0.89-1.22$ for $h=12 \mathrm{~mm}$. The FEA results can be considered as reasonable benchmark buckling pressures due to their close agreement with the experimental results in Table 4. Therefore, the safety factor ranges in Table 5 verify that the proposed design formula can predict the collapse pressure of filament-wound composite cylinders in the helical angle range of $5^{\circ}-70^{\circ}$ within around $20 \%$ error bound, which is an acceptable performance.

\section{Concluding remarks}

This study aimed to derive an empirical formula for predicting the collapse strength of filament-wound composite cylinders under external pressure loads. The formula was derived by curve-fitting of an experimental database and was verified by comparison with existing design formulations and nonlinear finite element method solutions. From the results, the following conclusions can be drawn.

(1) The proposed formula is able to predict the collapse pressure loads of composite cylinders as a function of important design parameters such as geometric dimensions and layered angles.

(2) One benefit of the proposed formula is that the effects of interaction between geometric and material nonlinearities, that is, between buckling and material failure (plasticity and fracture), are more precisely taken into account than in existing design formulations such as those of ASME and NASA.

(3) Furthermore, the proposed formula takes into account the effects of manufacturing imperfections by introducing a reduction factor into the collapse strength.

(4) It is, however, noted that the applicability of the proposed formula has only been studied for helical angles in the range $5^{\circ}-70^{\circ}$.

Acknowledgements 
The corresponding author acknowledges the support of the Korea Ship and Offshore Research Institute (International Centre for Advanced Safety Studies, ICASS) which has been a Lloyd's Register Foundation Research Centre of Excellence since 2008.

\section{References}

Abdel-Nasser, Y., Elhewy, A.M.H. and Al-Mallah, I., 2015. Impact analysis of composite laminate using finite element method. Ships and Offshore Structures, 12(2): 219-226.

Aguirre, F., Vargas, S., Valdes, D., and Tornero, J., 2017. State of the art of parameters for mechanical design of an autonomous underwater vehicle. International Journal of Oceans and Oceanography, Vol.11(1), pp.89-103.

ASME Boiler and Pressure Vessel Code, 2007.Section X: Fiber-Reinforced Plastic Pressure Vessel.

Bai, Y., Xu, W., Cheng, P., Wang, N. and Ruan, W., 2013a. Behaviour of reinforced thermoplastic pipe (RTP) under combined external pressure and tension, Ships and Offshore Structures, 9(4):464-474.

Bai, Y., Yuan, J., Qiao, H., Cheng, P. and Cao, Y., 2014. Behaviour of reinforced thermoplastic pipe under combined bending and external pressure. Ships and Offshore Structures, 10(5): 575-586.

Bai, Y., Ruan, W., Cheng, P., Yu, B. and Xu, W., 2013b. Buckling of reinforced thermoplastic pipe (RTP) under combined bending and tension. Ships and Offshore Structures, 9(5): 525-539.

Burcher, R. and Rydill, L., 1994. Concepts in Submarine Design. Cambridge University Press: Cambridge, U.K.

Barbero, E.J. and Reddy, J.N., 1990. General two-dimensional theory of laminated cylindrical shells. AIAA Journal, Vol.28(3), pp.544-553.

Blachut, J., 2016. Buckling of composite domes with localized imperfections and subjected to external pressure. Composite Structures, Vol.153, pp.747-754.

Castro, S.G.P., Mittelstedt, C., Monteiro, F.A.C., Degenhardt, R., and Ziegmann, G., 2015. Evaluation of non-linear buckling loads of geometrically imperfect composite cylinders and cones with the Ritz method. Composite Structures, Vol. 122, pp.284-299.

Cho, J.R., Chung, W.B., and Kim, J.S., 2009. UVRC, Division of underwater structure and vibration research, 2nd Phase Report, ADDR-413-091956, Daejeon: Agency for Defense Development, Republic of Korea.

Dey, A., Choudhury, P.L., and Pandey, K.M., 2014. A computational study of buckling analysis of filament wound composite pressure vessel subjected to hydrostatic pressure. Global Journal of Researches In Engineering A: Mechanical and Mechanics Engineering, Vol.14(2), pp.9-14.

Graham, D., 1995. Composite pressure hulls for deep ocean submersibles. Composite Structures, Vol.32, pp.331-343.

Graham, D., 1996. Buckling of thick-section composite pressure hulls. Composite Structures, Vol.35, pp.5-20.

Guz, I., Menshykova, M. and Paik, J.K., 2014. Thick-walled composite tubes for offshore applications: an example pf stress and failure analysis for filament-wound multi-layered pipes. Ships and Offshore Structures, 12(3): 304-322.

Hur, S.H., Son, H.J., Kweon, J.H., and Choi, J.H., 2008. Postbuckling of composite cylinders under external hydrostatic pressure. Composite Structures, Vol. 86, pp.114-124. 
Jones, R.M., 1999. Mechanics of Composite Materials. Taylor \& Francis, Inc.: Philadelphia, USA.

Jones, N., 2010. Some recent developments in the dynamic inelastic behavior of structures. Ships and Offshore Structures, 1(1): 37-44.

Jung, H.Y., Cho, J.R., Han, J.Y., Lee, W.H., Bae, W.B. and Cho, Y.S., 2012. A study on buckling of filament-wound cylindrical shells under hydrostatic external pressure using finite element analysis and buckling formula. International Journal of Precision Engineering and Manufacturing, Vol. 13(5), pp.731-737.

Kim, M.H., Cho, J.R., Bae, W.B., Kweon, J.H., Choi, J.H., Cho, S.R., and Cho, Y.S., 2010. Buckling analysis of filament-wound thick composite cylinder under hydrostatic pressure.International Journal of Precision Engineering and Manufacturing, Vol. 11(6), pp.909-913.

Lee, S.E., Sahin, S., Rigo, P., Park, M. and Paik, J.K., 2016. Ultimate strength of cylindrical shells with cutouts. Ships and Offshore Structures, 12(Sup 1): S153-S173.

Li, Z.M. and Lin, Z.Q., 2010. Non-linear buckling and postbuckling of shear deformable anisotropic laminated cylindrical shell subjected to varying external pressure loads. Composite Structures, Vol. 92, pp.553-567.

Liang, C.C., Chen, H.W., and Jen, C.Y., 2003. Optimum design of filament-wound multilayer-sandwich submersible pressure hulls.Ocean Engineering, Vol.30, pp.19411967.

Messager, T., 2001. Buckling of imperfect laminated cylinders under hydrostatic pressure. Composite Structures, Vol. 53, pp.301-307.

Messager, T., Pyrz, M., Gineste, B., and Chauchot, P., 2002. Optimal laminations of thin underwater composite cylindrical vessels. Composite Structures, Vol. 58, pp.529-537.

Moon, C.J., Kim, I.N., Choi, B.H., Kweon, J.H., and Choi, J.H., 2010. Buckling of filamentwound composite cylinders subjected to hydrostatic pressure for underwater vehicle applications. Composite Structures, Vol. 92, pp.2241-2251.

Mouritz, A.P., Gellert, E., Burchill, P., and Challis, K., 2001. Review of advanced composite structures for naval ships and submarines. Composite Structures, Vol. 53, pp.21-41.

NASA Space Vehicle Design Criteria, 1968. Buckling of Thin-Walled Circular Cylinders. NASA SP-8007, pp.19-21, Washington, D.C.: National Aeronautics and Space Administration, USA.

Nguyen, H.L.T., Elishakoff, I., and Nguyen, V.T., 2009. Buckling under the external pressure of cylindrical shells with variable thickness. International Journal of Solids and Structures, Vol.46, pp.4163-4168.

Papadakis, G., 2008. Buckling of thick cylindrical shells under external pressure: A new analytical expression for the critical load and comparison with elasticity solutions. International Journal of Solids and Structures, Vol.45, pp.5308-5321.

Perry, T.G., Douglas, C.D., and Gorman, J.J., 1992. Analytical design procedures for buckling-dominated graphite/epoxy pressure hulls. SNAME Transactions, Vol. 100, pp.93-115.

Qatu, M.S., Asadi, E., and Wang, W., 2012. Review of recent literature on static analyses of composite shells: 2000-2010. Open Journal of Composite Materials, Vol.2, pp.61-86.

Rais-Rohandi, M. and Lokits, J., 2007. Reinforcement layout and sizing optimization of composite submarine sail structures. Structural Multidisciplinary Optimization, Vol.34, pp.75-90.

Rao Yarrapragada, K.S.S., Mohan, R.K., and Kiran, B.V., 2012. Composite pressure vessels. International Journal of Research in Engineering and Technology, Vol.01(04), pp.597618. 
Reddy, J.N.,1984. Exact solutions of moderately thick laminated shell. Journal of Engineering Mechanics, Vol.110(5), pp.794-809.

Schillo, C., Röstermundt, D., and Krause, D., 2015. Experimental and numerical study on the influence of imperfections on the buckling load of unstiffened CFRP shells. Composite Structures, Vol. 131, pp.128-138.

Smith, M., Macadam, T. and MacKay, J.R., 2013. Integrated modelling, design and analysis of submarine structures. Ships and Offshore Structures, 10(4):349-366.

Soldatos, K.P., 1992. Nonlinear analysis of transverse shear deformable laminated composite cylindrical shells - Part I: Derivation of governing equations. Journal of Pressure Vessel Technology, Vol.114, pp.105-109.

Soldatos, K.P., 1992. Nonlinear analysis of transverse shear deformable laminated composite cylindrical shells - Part II: Buckling of axially compressed cross-ply circular and oval cylinders. Journal of Pressure Vessel Technology, Vol.114, pp.110-114.

Starbuck, J.M. and Blake, H.W., 1994. Failure of thick composite cylinders subjected to external hydrostatic pressure. Compression Response of Composite Structures, ASTM STP 1185, pp.159-174, Philadelphia: American Society for Testing and Materials, USA.

Xiong, H., Bai, Y., Fang, Q. and Tang, G., 2017. Analysis on the ultimate bearing capacity of plastic pipe reinforced by cross-helically winding steel wires under internal pressure. Ships and Offshore Structures, 13(Sup 1):264-272. 